\title{
COAGULATION ACTIVITY AND D-DIMER IN SEPSIS PATIENTS
}

\author{
Anggraini $\mathrm{D}^{1}$, Maani $\mathrm{H}^{2}$, Rofinda $\mathrm{ZD}^{2}$ \\ ${ }^{1}$ Department of Clinical Pathology, Faculty of Medicine, Baiturrahmah University, Padang, Indonesia. E-mail: \\ dbiepatklin@gmail.com. ${ }^{2}$ Department of Clinical Pathology, Faculty of Medicine, Andalas University/Dr.M. Djamil Hospital, \\ Padang, Indonesia
}

\section{ABSTRACT}

Sepsis is a systemic inflammatory response with the presence of suspected or proven infection. The inflammation will increase the production of proinflammatory cytokines that will activate coagulation and suppress fibrinolytic system. An imbalance of hemostasis mechanism and inflammation in sepsis can progress into Disseminated Intravascular Coagulation (DIC). The objective of this study was to determine the coagulation activity (platelet count, Prothrombin Time (PT), activated Partial Thromboplastin Time (aPTT)), and D-dimer in sepsis patients. A descriptive study was conducted at the Dr. M. Djamil Hospital on December 2012-July 2013. Subjects were adult patients with two or more of four criteria for Systemic Inflammatory Response Syndrome (SIRS) and presence of suspected or proven infection admitted to the Department of Internal Medicine. Laboratory examination was conducted in the Clinical Pathology Laboratory Dr. M. Djamil Hospital including the coagulation activity and D-dimer level. Data were processed manually and presented in distribution tables, and diagrams. Subjects of this study were 54 sepsis patients, consisting of $57 \%$ males and $43 \%$ females with a median age of 53.5 year-old, platelet count 188.5 x 103/ $\mu \mathrm{L}$, PT 13.7 seconds, aPTT 39.3 seconds, and D-dimer level $1.15 \mu \mathrm{g} / \mathrm{mL}$. Based on this research it can be concluded that coagulation activity in sepsis patients showed that platelets count were still in the normal range while PT and aPTT were prolonged and D-dimer levels were increased.

Key words: Coagulation activity, D-dimer, sepsis

\section{INTRODUCTION}

The American College of Chest Physicians (ACCP) and The Society for Critical Care Medicine (SCCM) define sepsis as an inflammatory reaction with symptoms of systemic inflammatory response with the presence of suspected or proven infection. ${ }^{1}$ Sepsis is a continuous process that started from infection, SIRS, sepsis, severe sepsis, septic shock and multiorgan dysfunction that can lead to death. ${ }^{2}$

The incidence of sepsis reached 750,000 cases a year and more than $28.6 \%$ or about 210,000 died. $^{3}$ The most common complication of sepsis is multiple organ failures, which consists of liver dysfunction in $20 \%-50 \%$ of sepsis patients with DIC and $25 \%-67 \%$ of sepsis cases with renal dysfunction. ${ }^{4}$ Engel et al. reported that severe sepsis could cause death by $63 \%$ due to renal dysfunction. ${ }^{5}$

Normal body responses to fight infections in sepsis is by releasing a wide variety of pro- inflammatory mediators that can stimulate activation of coagulation system in sepsis initially stimulated by the tissue factor pathway (extrinsic pathway), mediated by several pro-inflammatory cytokines. Extrinsic pathway the dominant mechanism that activates the coagulation system in sepsis will eventually increase production of thrombin. ${ }^{6}$ Contact factors in the intrinsic pathway are also activated due to endothelial damage caused by bacteria and its substances that increases fibrin formation. The cascade of coagulation in sepsis causes an imbalance of hemostasis mechanism accompanied by inflammation that can progress to Disseminated Intravascular Coagulation (DIC). ${ }^{6,7}$ The coagulation activity can be assessed by examination of the platelet count, PT, and aPTT. Fibrinolysis function decreases in sepsis despite persisting coagulation activity, causing greatly increased fibrin formation and eventually microvascular thrombosis. Fibrinolysis activity can be assessed by D-dimer measurement. $^{8,9}$ 
There are no studies about coagulation activities and D-dimer in sepsis patients at the Dr. M. Djamil Hospital, Padang. The aimed of this study was to determine the coagulation activity (platelet count, PT, aPTT) and D-dimer in sepsis patients.

\section{METHODS}

A descriptive study was conducted at the $\mathrm{Dr}$. M. Djamil Hospital during December 2012-July 2013. Subjects of this study were patients who met the inclusion and exclusion criteria. The inclusion criteria were adult patients with two or more of four criteria for SIRS and presence of suspected or proven infection who were willing to participate in this study by signing an informed consent. Exclusion criteria were patients that received anticoagulant therapy, with liver and kidney dysfunction. Samples were seven $\mathrm{mL}$ blood obtained by venous puncture consisting of three $\mathrm{mL}$ EDTA blood for platelet count, two $\mathrm{mL}$ citrated blood for PT-APTT examination, and two $\mathrm{mL}$ heparinized blood for D-dimer examination. The method of PT-aPTT examination was by electromechanical clot detection and the method of D-Dimer examination by ELISA method. The data were processed manually, and presented in distribution tables and diagrams.

\section{RESULTS AND DISCUSSION}

This research was conducted on 54 sepsis patients who were admitted to the Department of Internal Medicine, Dr. M. Djamil Hospital, Padang from December 2012 to July 2013. Data on age, gender, the activity of coagulation parameters and levels of Ddimer were recorded for all patients. This study comprised sepsis patients characteristics by age, sex and the median age of patients with sepsis was 53.5 years, the highest percentage suffered by the elderly group $70.4 \%$ and in adult group $29.6 \%$. Distribution of sepsis patients was based on gender, $57 \%$ males and 43\% females (Table 1 ).

Table 1. Characteristic of 54 sepsis patients

\begin{tabular}{ll}
\hline Total patients (person) & 54 \\
Age (median; range) & 53.5 years old (21-74) \\
18-59 years old (adult) & $29.6 \%$ \\
$>60$ years old (elderly) & $70.4 \%$ \\
Sex & \\
Males & $57 \%$ \\
Females & $43 \%$ \\
\hline
\end{tabular}

Sepsis patients had normal platelet counts $59 \%(32 / 54)$ and with thrombocytopenia $41 \%$ (22/54) (Table 2).

Table 2. Frequency distribution of platelet counts in sepsis patients

\begin{tabular}{llll}
\hline No & Thrombocyte counts & Frequences & $\%$ \\
\hline 1 & Normthrombocytes & 32 & 59 \\
2. & Low thrombocytes & 22 & 41 \\
\hline
\end{tabular}

Sepsis patients with shortened PT, normal PT, and elevated PT were $5.6 \%, 42.6 \%$, and $51.8 \%$ (Table 3). Sepsis patients with shortened aPTT, normal aPPT, and elongated aPPT were $11 \%, 33.4 \%$, and $55.6 \%$ (Table 4).

Table 3. Frequency distribution of PT in sepsis patients

\begin{tabular}{lcc}
\hline PT (Sec) & Frequences & $\%$ \\
\hline$<9.9$ & 3 & 5.6 \\
$9.9-13.5$ & 23 & 42.6 \\
$>13.5$ & 28 & 51.8 \\
Total & 54 & 100 \\
\hline
\end{tabular}

Table 4. Frequency distribution of aPTT in sepsis patients

\begin{tabular}{ccc}
\hline aPTT (Sec) & Frequences & \% \\
\hline$<28$ & 6 & 11 \\
$28-37.8$ & 18 & 33.4 \\
$>37.8$ & 30 & 55.6 \\
Total & 54 & 100 \\
\hline
\end{tabular}

Sepsis patients with negative D-dimer $(\leq 0.5$ $\mathrm{ug} / \mathrm{mL}$ ) were $44.4 \%(24 / 54)$ and with positive Ddimer (>0.5 ug/mL) were 55.6\% (30/54) (Figure 1).

Coagulation activity and D-dimer in 54 sepsis patients, with a median of platelet counts $188.5 \mathrm{x}$ $10^{3} / \mu \mathrm{L}$, median of PT $13.7 \mathrm{sec}$, median of aPTT 39.3 sec and median of D-dimer level $1.15 \mathrm{ug} / \mathrm{mL}$ (Table $5)$.

Table 5. Coagulation activity and D-dimer level in 54 sepsis patients

\begin{tabular}{cc}
\hline Parameters & Median (range) \\
\hline Thrombocyte counts & $188.5 \times 10^{3} / \mu \mathrm{L}\left(12 \times 10^{3}-\right.$ \\
& $\left.503 \times 10^{3}\right)$ \\
PT & $13.7 \mathrm{sec}(9.2-96.9)$ \\
aPTT & $39.3 \mathrm{sec}(23.9-180)$ \\
D-dimer level & $1.15 \mu \mathrm{g} / \mathrm{mL}(0.1-4)$ \\
\hline
\end{tabular}




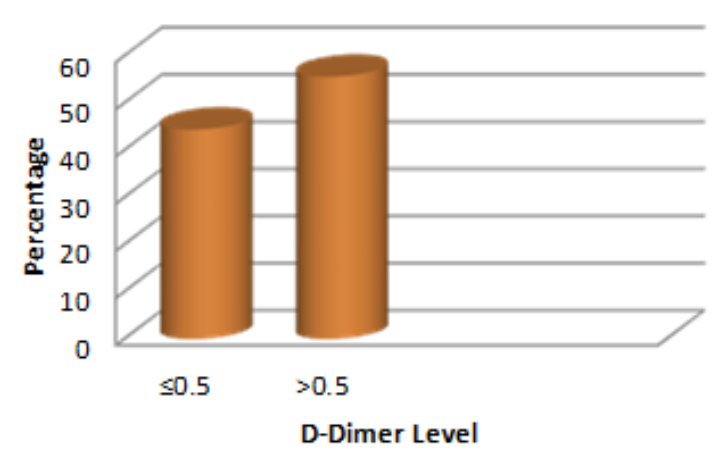

Figure 1. D-dimer level in sepsis patients

The percentage of sepsis patients that investigated based on age in this study over 60 years old (elderly) were $70.4 \%$, with a median of age 53.5 years old (21-74 years). Oberhofer et al. reported that the median of age in sepsis patients was 66 years-old (22-77 years) in Kroasia. ${ }^{10}$ This condition is associated with immune system function decreasing with age. The ability of immunity decreased in infection. ${ }^{11,12}$ Sepsis patients in this study consisted of males 57\% (30 people) and females $43 \%$ (24 people), while Park et al. reported sepsis patients in Korea composed of $48 \%$ males and $52 \%$ females. ${ }^{13}$

This study showed that the median of platelet count was in normal limits $188.5 \times 10^{3} / \mu \mathrm{L}$ $\left(12 \times 10^{3}-503 \times 10^{3}\right)$, it was not different from a research by Lorente et al. in Spain, who reported a median of platelet counts in sepsis patients $192 \times 10^{3} / \mu \mathrm{L}\left(131 \times 10^{3}-273 \times 10^{3}\right){ }^{14}$ This study found thrombocytopenia in $40.7 \%$ of sepsis patients. Thrombocytopenia state is a marker of failure in bone marrow functions in maintaining hemostasis due to excessive consumption on DIC and endothelial damage because of diffuse inflammatory process. $^{15,16}$

Median of PT was 13.7 seconds in this study (9.2-96.9 seconds) showing elongated PT in 51.8\%, normal PT $42.6 \%$, and shortened PT $56 \%$ in sepsis patients. Kinasewitz et al., in the United States also obtained elongated PT with a median of $18.7 \mathrm{sec}-$ onds (16.5-22 seconds). ${ }^{17}$ Estrin et at., in the United States researched on sepsis-DIC animals, with a median of PT 12.8 seconds. ${ }^{18}$

This study showed a median of APTT 39.3 seconds (23.9-180 seconds), elongated aPTT 55.6\%, normal aPTT $33.4 \%$, and shortened aPTT $11 \%$.
Lorente et al. reported a median value of aPTT in sepsis patients in the normal limit of 32 seconds. ${ }^{14}$

Fibrinolysis activity assessed by examination of D-dimer levels, increased with a median $1.15 \mu \mathrm{g} / \mathrm{mL}$ ( 0.1 to $4 \mu \mathrm{g} / \mathrm{mL}$ ), it was same as Kinasewitz's study in 2004, who found a median of D-dimer $4.2 \mathrm{ug} / \mathrm{mL}$ (2.2$8.4 \mathrm{\mu g} / \mathrm{mL}){ }^{17}$ Mayrommatis et al. reported 40 of 82 patients with sepsis had positive D-dimer levels $(>0.5$ $\mu \mathrm{g} / \mathrm{mL}) .{ }^{19}$ This study showed that D-dimer levels were positive in 30 sepsis patients (55.6\%).

Thrombocytopenia, prolongation of PT and aPTT, increased levels of D-dimer in sepsis is a description of hemostasis function disorder due to the occurrence of DIC and as a parameter for detecting sepsis complications. ${ }^{16}$ These results were associated with the occurrence of a hypercoagulable state due to activation of coagulation, caused by proinflammatory cytokines that were increased in early sepsis. Normal liver function a compensated situation leading to the value of PT and aPTT shortened or normal in sepsis. ${ }^{15}$

\section{CONCLUSION AND SUGGESTION}

The normal range of platelet counts, prolonged PT and APTT, and positive D-dimer levels are coagulation activities that can be found in sepsis patients. There is a widespread agreement that dysfunctions in coagulation develop during sepsis and lead to inappropriate intravascular fibrin deposition. Any consensus beyond that statement, however, remains frustratingly elusive. In patients with severe sepsis and Disseminated Intravascular Coagulation (DIC), the parameters should be determined for detecting complications sepsis such as fibrinogen levels in order to diagnose DIC, and some of the proinflammatory cytokines that increased in early sepsis.

\section{REFERENCES}

1. American College of Chest Physicians. Definition for sepsis and organ failure and guidelines for the use of innovation therapies in sepsis. In: Crit care med. 1992; 86474.

2. Hague KN. Definition of bloodstream infection in newborn. In: Pediatr crit care met. 2005; 6(3): 45-9.

3. Angus DC, Linde-Zwirble WT, Lidicker J. Epidemiology of severe sepsis in United States. In: Crit care med, 2001; 29(7): 1303-10.

4. Siegal T, Seligsohn U, Aghai E. Clinical and laboratory aspects of disseminated intravascular coagulation (DIC): A study of 118 cases. In: J Thromb Haemost. 1978; 39 (1): 122.

5. Engel C, Brunkhorst F, Bone HG, Brunkhorst R, Gerlach H, Grond S. Epidemiology of sepsis in Germany: Results fro 
a national prospective multicenter study. In: Intensive care med. 2007; 33(4): 606-18.

6. Chu AJ. Tissue factors, blood coagulation, and beyond. In: Intrn J Inflams. 2011; 2011: 1-30.

7. Root RK, Jacobs R. Septicemia and septic shock. In: Wilson JD, Braunwald E, Isselbacker KJ, et al. Eds. Harison's Principles of Internal Medicine. $12^{\text {th }}$ Ed. New York, McGraw- Hill, 1991; 502-7.

8. Hoffman R. Hematology: Basic principles and practice. $3^{\text {rd }}$ Ed., Philadelphia, Churcill Livingstone Inc. 2000; 1000-33.

9. Zeerleder S, Hack E, Wuielemin W. Disseminated intravascular coagulation in sepsis. In: Chest Journal. 2005; 128(4): 2864-75.

10. Dempfle CE. Coagulopathy of sepsis. In: Thromb Haemost journal. 2004; 91: 213-24.

11. Fatma. Respons imunitas yang rendah pada manusia usia lanjut. In: MKM FKUI, 2006; 01(10): 46-53.

12. Kresno SB. Respons imun pada inflamasi. Dalam: Imunologi Diagnosis dan prosedur Ed 5., Jakarta, Badan Penerbit Fakultas Kedokteran Universitas Indonesia, 2010; 213-25.
13. Park R, Song J, Soo S. Elevated level of activated and inactivated thrombin activable fibrinolysis inhibitor in patien sepsis. In: Korean Journal of Hematology 2010; 45(4): 264-68.

14. Lorente L, Martin M, Gonzalez PA, Rodriquez AD, Labarta $\mathrm{L}$, Diaz $\mathrm{C}$ et al. Prognostic value of malondialdehyde serum levels in severe sepsis. 2013; 8(1): 1-5.

15. Munford RS. Severe sepsis and septic shock. In: Harrison's Principles of internal medicine. $16^{\text {th }}$ Ed., 2005; 1606-11.

16. Reinhart K, Meisner M, Brunkhorst FM. Markers for sepsis diagnostics. In: Crit Care Clin. 2006; 22(3); 503-19.

17. Kinazewits GT, Yan SB, Basson B, Comp P, Russel JA, Cariou $A$, et al. Universal changes in biomarkers of coagulation and inflammation occur in patients with severe sepsis, regardless of causative micro-organism. In: Crit Care 2004; 8(2): 82-90.

18. Estrin MA, Wehausen CE, Jessen CR, Lee JA. SepsisDisseminated intravascular coagulation in cats. In: J Vet Intern Med. 2006; 20(6): 1334-9.

19. Mavrommatis AC, Theodoritis T, Economou M, Eli E, Kokkinou $C$, et al. Activation of the fibrinolytic system and utilization of coagulation inhibitor in sepsis. In: Journal of Intensive Care Med. 2001; 27(12): 1853-8. 